Brit. J. industr. Med., 1959, 16, 244.

\title{
THE ACTION EXERTED BY CERTAIN PNEUMOCONIOTIC FACTORS UPON THE ACID MUCOPOLYSACCHARIDE CONTENTS OF PULMONARY MACROPHAGES
}

\author{
BY \\ N. Gh. LUPU, DOINA VELICAN, C. VELICAN, and V. OLINESCU \\ From the Therapeutics Institute of the Academy of the Rumanian People's Republic, Bucharest
}

(RECEIVED FOR PUBLICATION JUNE 13, 1958)

Experimental inhalations of silicon dioxide and tobacco smoke cause a gradual increase in the number of pulmonary macrophages containing metachromatic material within the nucleus and cytoplasm, and they may assume the appearance of mast cells. Many pulmonary macrophages containing metachromatic material were found in anthracotic human lungs.

Histochemical techniques identify this material as acid mucopolysaccharides. After a more prolonged action of pneumoconiotic substances, mucopolysaccharides disappear after hyaluronidase extraction.

On the basis of these findings the increased amount of acid mucopolysaccharides in the connective interstices of the lung during the phase preceding the onset of fibrous lesions is explained by the prolonged irritative action of pneumoconiotic substances, which are believed to determine hypersecretion of acid mucopolysaccharides by the pulmonary macrophages.

In studying the histochemical features of the experimental process of pneumoconiotic fibrosis of the lungs (Lupu, Velican, Gociu, and Racoveanu, 1958), we found that during the phase which precedes the appearance of fibrous lesions metachromatic and P.A.S.-positive material accumulates in the connective interstices of the lung, disappearing almost completely after hyaluronidase extraction. It seems to play an important part in the development of fibrosis, as it is within this mass that precollagen fibres appear. We therefore attempted to learn whether the mucopolysaccharidic substance is secreted by pulmonary macrophages, and to this end investigated this process under conditions of hypersecretion by subjecting the reticular cells of the lung to the irritative effect of certain fibrogenic dusts, i.e., precisely those agents which in the long run determine the accumulation of acid mucopolysaccharides within the connective interstices of the lung.

We have not encountered any similar investigations in the available literature.

\section{Material and Method}

Experiments were carried out on 60 guinea-pigs, divided into two groups each of 30 animals.
The first group was exposed for four hours in a dusting room in which pure silicon dioxide was dispersed in a concentration of $15 \mathrm{mg} . / \mathrm{cu} . \mathrm{m}$.; the most frequent $(90 \%)$ particle size was 1-3 microns. Small groups of six animals were killed at various intervals after being removed from the dust (Table 1).

The other group was subjected to daily inhalations of tobacco smoke, each inhalation lasting 30 minutes. Groups of six animals were killed at one hour after the first inhalation, then after two, four, six, and 15 inhalations (Table 2).

Observations were also made in human subjects by the post-mortem collection of lungs displaying various degrees of anthracosis.

Smears were made from all the collected lungs and stained with toluidine blue, May Grünwald-Giemsa, methylene blue, Hotchkiss-McManus stain, and Best carmine stain. Enzymatic extraction techniques, using testicular hyaluronidase for 15 to 30 minutes at $37^{\circ} \mathrm{C}$., were applied, and the same cells were studied in comparative photomicrographs before and after being subjected to the action of the enzyme. As a control test, one half of each slide was subjected to inactivated hyaluronidase. "Pneumograms" were made of the smears from each of the lungs examined by counting 500 pulmonary macrophages, and obtaining the percentage of cells showing metachromatic granules. 


\section{Results}

"Pneumograms" on normal guinea-pigs after staining with toluidine blue showed pulmonary macrophages containing slightly metachromatic granules, the percentage varying from 0 to 2 . In the normal human lung this proportion is 5 to $6 \%$. The percentages of cells containing metachromatic material after the inhalation of silicon dioxide and inhalations of tobacco smoke are given in Tables 1 and 2. The human anthracotic lung showed areas in which the pulmonary macrophages contain mucopolysaccharides in a proportion ranging from 35 to $82 \%$.

TABLE 1

ONE EXPOSURE TO SILICON DIOXIDE DUST (EXPERIMENT 1)

\begin{tabular}{c|c|c}
\hline $\begin{array}{c}\text { No. } \\
\text { of } \\
\text { Animals }\end{array}$ & $\begin{array}{c}\text { Interval (in hours) at which } \\
\text { Animals were Killed after } \\
\text { Removal from Dust }\end{array}$ & $\begin{array}{c}\text { Pulmonary } \\
\text { Macrophages Showing } \\
\text { Metachromatic Granules } \\
(\%)\end{array}$ \\
\hline 6 & 24 & 4 \\
6 & 48 & 6 \\
6 & 72 & 10 \\
6 & 90 & 13 \\
6 & 120 & 14 \\
\hline
\end{tabular}

TABLE 2

DAILY INHALATIONS OF TOBACCO SMOKE (EXPERIMENT 2)

\begin{tabular}{c|c|c}
\hline $\begin{array}{c}\text { No. } \\
\text { of } \\
\text { Animals }\end{array}$ & $\begin{array}{c}\text { No. of Inhalations } \\
\text { before Sacrificing } \\
\text { Animals }\end{array}$ & $\begin{array}{c}\text { Pulmon ury } \\
\text { Macrophages Showing } \\
\text { Metachromatic Granules } \\
(\%)\end{array}$ \\
\hline 6 & 1 & 8 \\
6 & 2 & 14 \\
6 & 4 & 18 \\
6 & 6 & 21 \\
6 & 15 & 24 \\
\hline
\end{tabular}

Metachromatic material appeared both in cells containing inclusions and in those which harboured no foreign bodies within the nucleus and cytoplasm. There seems to be no direct relationship between the number of phagocytosed particles and the amount of metachromatic material detected in the respective cell; on the contrary, this material was more abundant within the cells containing some or few inclusions.

Such observations cannot be recorded as clearly in sections because the acid mucopolysaccharides in each cell are partially or wholly removed by the microscopic techniques.

As regards the intracellular pattern formed by the metachromatic material, the following aspects are more characteristic: The substance may be spread diffusely or in the shape of granules, both in the nucleus and in the protoplasm (Fig. 1). In some of the cells, all of the metachromatic material was concentrated in the nucleus, which appears as an intensely metachromatic spot, without any visible structure (Fig. 2). In other cells it was exclusively located in the protoplasm in the shape of small pulverous granules displaying low or moderate metachromasia ( $\alpha$ and $\beta$ metachromasia according to Pearse's classification), sometimes assuming a mast cell appearance. In other cells, the metachromatic material was seen both in the nuclei and in the cytoplasm. In the nuclei it seemed to be concentrated most frequently within the nucleolus or around it and around the nuclear membrane. In the cytoplasm it surrounded the nucleus and especially the intracytoplasmic inclusions (Fig. 3).

As regards the cytochemical characteristics, these substances are soluble in water on unfixed material. After toluidine blue staining, decolorizing, washing with water and restaining by the same stain, they disappear almost completely. This is why previous fixation by absolute alcohol is necessary for the study of the enzymatic action. The Hotchkiss-McManus reaction was strongly positive; in the same cell its intensity sometimes exceeded that of the area of metachromatic reaction, both in the nucleus and in the cytoplasm (Fig. 4). Best carmine staining yielded negative results.

Testicular hyaluronidase extraction was constantly negative or uncertain in animals killed shortly after the inhalation of tobacco smoke or silicon dioxide. In smears of human anthracotic lungs we could see that after extraction the metachromatic material had entirely disappeared in most of the macrophages investigated both before and after enzymatic action (Fig. 5), but in those cells in which mucopolysaccharide films were present around coal inclusions, enzymatic extractions generally failed to bring about changes.

\section{Discussion}

The results obtained with "pneumograms" and hyaluronidase extractions showed that after the action of certain pneumoconiotic factors the amount of acid mucopolysaccharides contained in pulmonary macrophages is significantly increased, as may be shown by ordinary histochemical tests.

During the initial phase of the appearance of these substances, they are not extractable by testicular hyaluronidase; this may prove that neither hyaluronic acid nor chondroitin sulphuric acid contribute to their formation during this period. At a more advanced stage, the amount of metachromatic material elaborated by pulmonary macrophages increases, and at the same time its chemical composition seems to change, when it is partially formed of the above-mentioned acids as well as by 


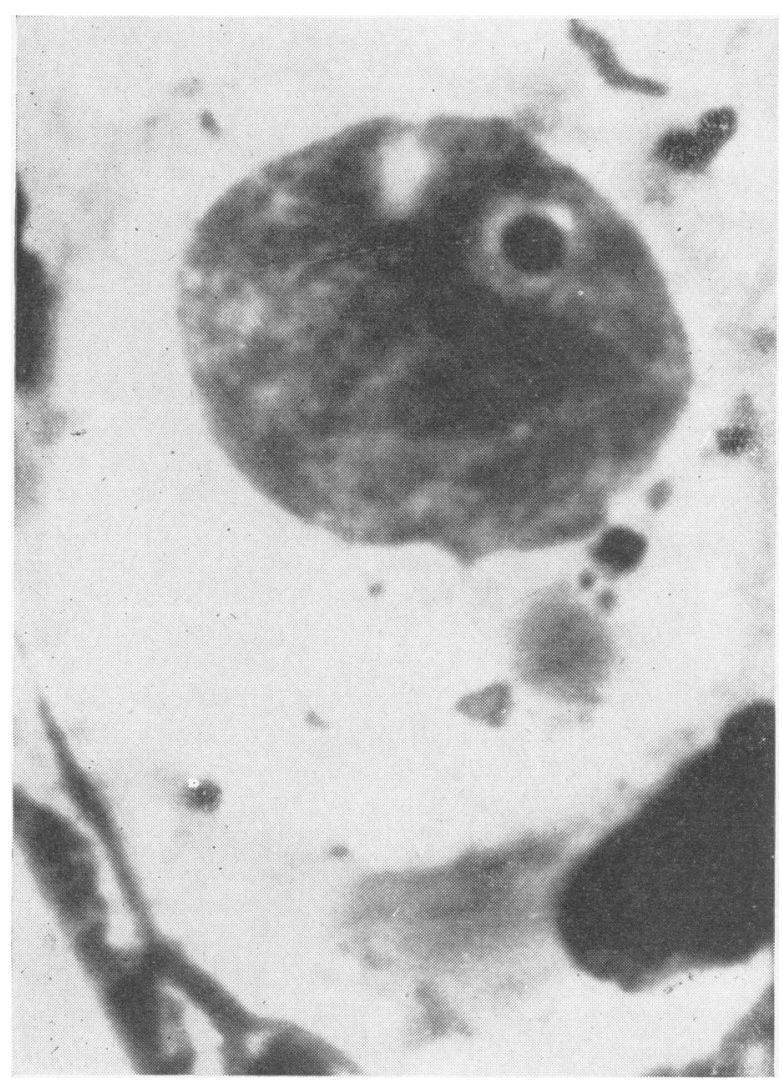

Fig. 1.-Macrophage in a pulmonary smear from animals subjected to five inhalations of tobacco smoke. A vesicle may be seen in the nucleus, containing a globule of intensely metachromatic material. It is surrounded by a diffuse intranuclear agglomeration of the same substance. Toluidine blue $\times 3,000$.

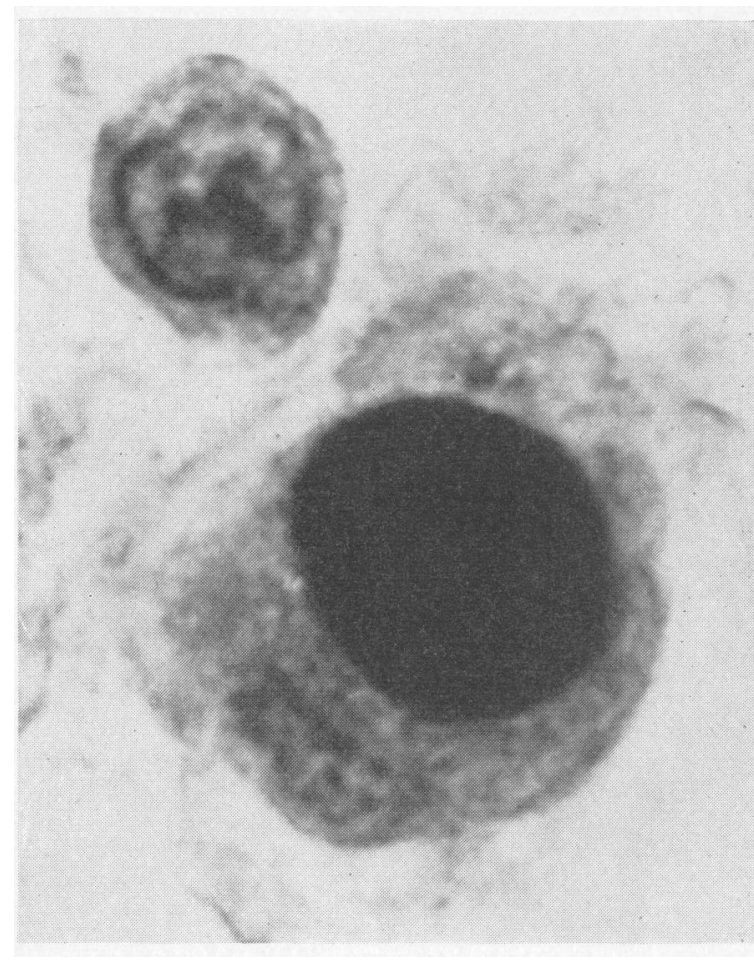

FIG. 2.-Macrophage in a lung section from animals subjected to a single inhalation of silicon dioxide and sacrificed 120 hours later. The whole nucleus displays intense and diffuse metachromasia. Toluidine blue $\times 3,000$.

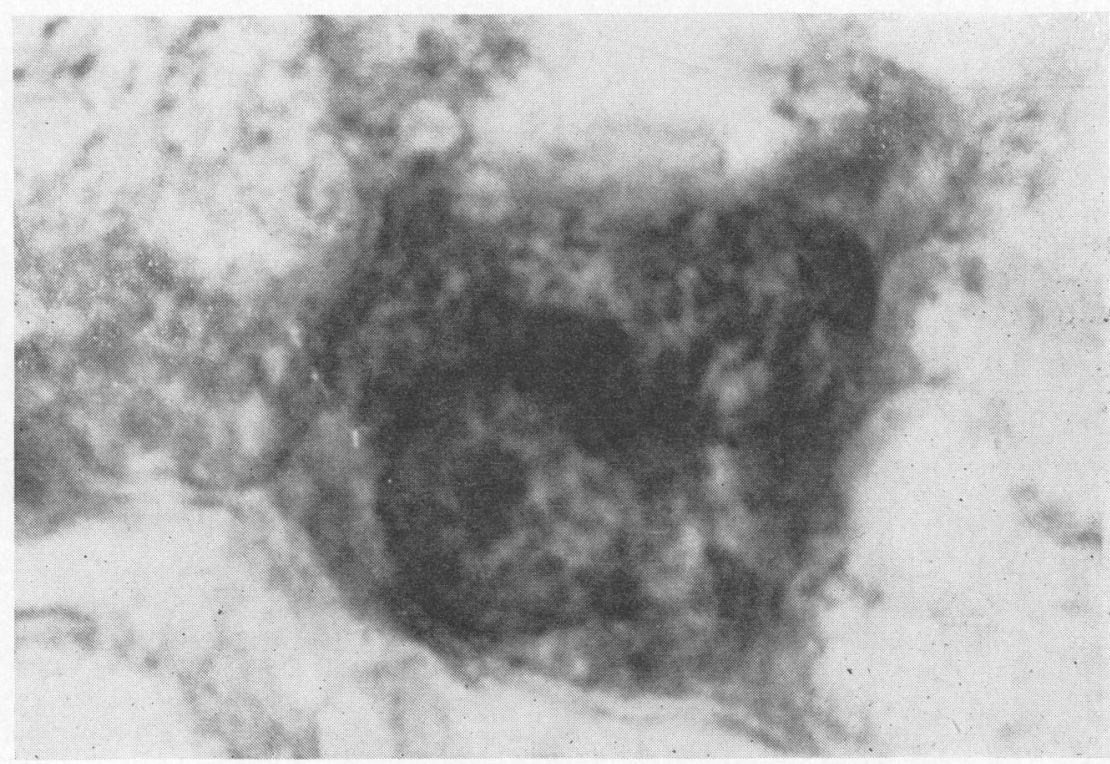

FIG. 3.-Macrophage in a lung section from animals subjected to 15 inhalations of tobacco smoke. Considerable amounts of intranuclear and intracytoplasmic metachromatic material may be seen, especially around the nucleus. Toluidine blue $\times 3,000$. 

FIG. 4.- Macrophage in a lung section
from animals subjected to 15 inhalations of tobacco smoke.

(a) The nucleus is intensely and diffusely metachromatic. The cytoplasm is likewise diffusely, but less intensely metachromatic.

Toluidine blue $\times 2,000$.

(b). The same cell after P.A.S. staining. Both the nucleus and the entire cytoplasm are intensely and diffusely stained.

Hotchkiss-McManus stain $\times 2,000$

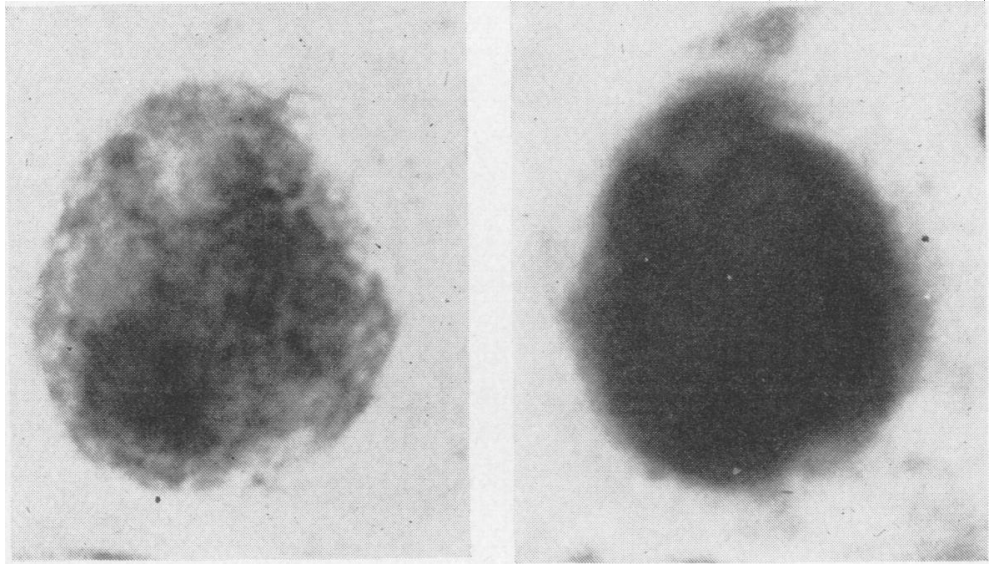

FIG $4 a$.

FIG. $4 b$

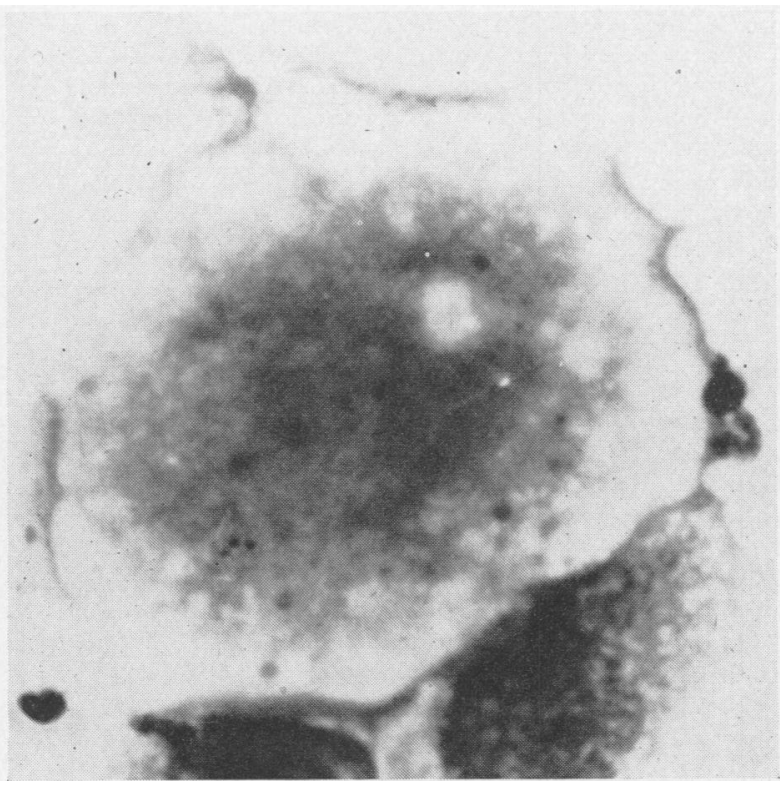

FIG. 5.-Human pulmonary macrophage in a smear from a case of anthracosis

(a) The nucleus is covered by a slightly metachromatic substance.

hyaluronidase extractions performed in preparations of human lungs with anthracosis.

Our investigations justify relating the appearance of acid mucopolysaccharide substances in pulmonary macrophages immediately after the action of certain pneumoconiotic agents to the massive increase of these substances in the connective interstices of the lung during the periods preceding the development of the fibrous process. This accumulation of metachromatic material appears to be the result of an exaggerated secretion of the pulmonary macrophages as a result of the prolonged action of pneumoconiotic factors.

The results of our study do not support the

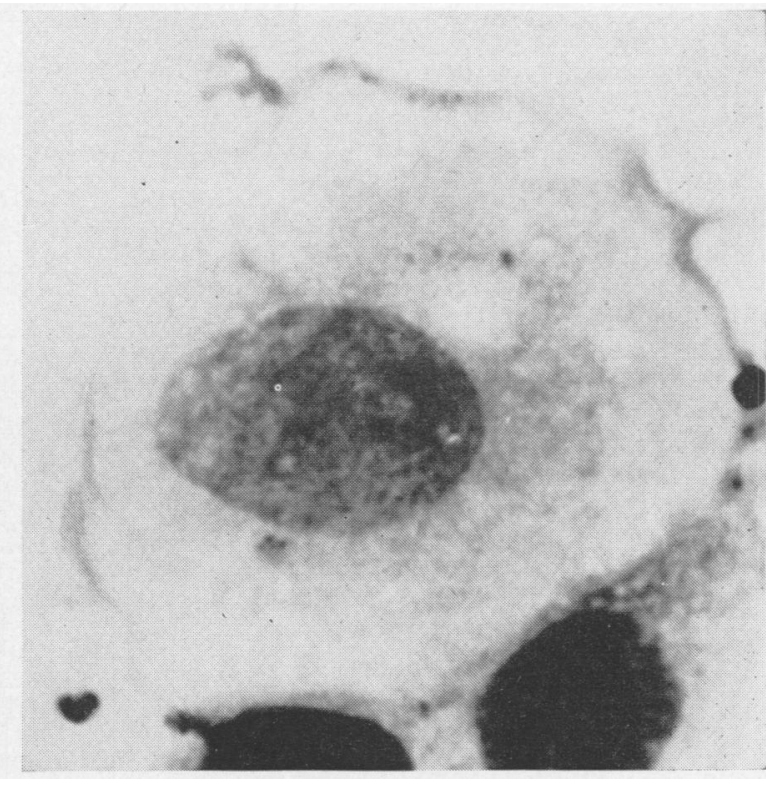

(b) After hyaluronidase extraction this substance disappears altogether. Toluidine blue stain, hyaluronidase extraction, and restaining with toluidine blue, $\times 3,500$.

hypothesis concerning the secretion of acid mucopolysaccharides by fibroblasts (Burkl, 1952; Wirtschafter, 1957), i.e., by the same elements which are supposed to participate in the formation of collagen fibres. In the normal guinea-pig lung, as in the one subjected to the brief action of pneumoconiotic factors, no such cells can be demonstrated and the data resulting from the present note solely concern elements of the reticulo-histiocytic type.

\section{REFERENCES}

Burkl, W. (1952). Wien. klin. Wschr., 64, 411 Lupw, N. Gh., Velican, C., Gociu, M., and Racoveanu, C. (1958). Morfol norm, si pat., 3, 11.

Wirtschafter, Z. T. (1957). A,M.A. Arch. Path., 64, 577. 